\title{
Phytochemical composition and essential mineral profile, antioxidant and antimicrobial potential of unutilized parts of jackfruit
}

\author{
*Adan, A.A., Ojwang, R.A., Muge, E.K., Mwanza, B.K. and Nyaboga, E.N. \\ Department of Biochemistry, University of Nairobi, P.O. Box 30197-00100, Nairobi, Kenya
}

Article history:

Received: 30 September 2019

Received in revised form: 22

November 2019

Accepted: 26 February 2020

Available Online: 1 April

2020

\section{Keywords:}

Artocarpus heterophyllus,

Solvents,

Phytochemicals,

Radical scavenging capacity,

Antibacterial activity

\section{DOI:}

https://doi.org/10.26656/fr.2017.4(4).326

\begin{abstract}
The processing of jackfruit (Artocarpus heterophyllus Lam) yields a considerable amount of bio-waste. Accumulation of this waste is considered a health risk because it is a potential source of air and water pollution. Recycling of the unutilized fruit parts, therefore, reduces the quantity and the impact of the bio-waste released to the environment. The purpose of this study was to determine the phytochemical profile, antioxidant and antimicrobial activities of extracts from three fruit parts (peel, fiber and the core) of jackfruit sampled from the coastal region of Kenya. Different extraction techniques and solvents were tested. The highest phenolic and flavonoid content of the peels, fiber and the core were obtained from methanol extracts following a 48-hour incubation. The values were recorded at $17.07 \pm 5.16 \mathrm{mg} / \mathrm{g}, 23.28 \pm 4.73 \mathrm{mg} / \mathrm{g}$, and $15.68 \pm 3.74 \mathrm{mg} / \mathrm{g}$ for the phenolics and $28.55 \pm 12.42 \mathrm{mg} / \mathrm{g}, 35.4 \pm 9.53 \mathrm{mg} / \mathrm{g}$ and $36.23 \pm 2.54 \mathrm{mg} / \mathrm{g}$ for the flavonoids, respectively. The highest tannin content was obtained from distilled water extracts following homogenization recorded at $10.82 \pm 2.63 \mathrm{mg} / \mathrm{g}$, $10.39 \pm 4.10 \mathrm{mg} / \mathrm{g}$ and $10.52 \pm 1.05 \mathrm{mg} / \mathrm{g}$ for peels, fiber and core, respectively. The fiber extracts gave the highest 2,2-diphenyl-1-picrylhydrazyl (DPPH) scavenging activity followed by the core at $61.51 \pm 29.90 \%$ and $51.06 \pm 33.39 \%$, respectively. The antioxidant activity was highest for methanol fiber extracts at $61.51 \pm 29.90 \%$ for DPPH radical scavenging activity and $7.94 \pm 4.56 \mathrm{mg} / \mathrm{mL}$ for reducing power assay. The best antibacterial activity against Xanthomonas axonopodis pv. manihotis (Xam) was obtained from Ethyl acetate extracts showed. The unutilized jackfruit parts, therefore, are a potential source of natural antioxidants as well as antibacterial, for agriculture and food industry.
\end{abstract}

\section{Introduction}

The disposal of unutilized parts of fruits is a key environmental concern because of increased bio-waste accumulation. The waste is considered a potential breeding ground for food-borne and water-borne pathogens (Feumba et al., 2016). According to Hoornweg et al. (2013), global waste is estimated to be 1.3 billion tons annually and may increase to 2.2 billion tonnes by 2025 . The main sources of the bio-waste are factories, such as the fruit juice processing plants in the food industry that leave huge accumulation of unutilized parts of the fruits (Asquieri et al. 2008). Therefore, there is a need to recycle unutilized parts of fruits to prevent their bioaccumulation. Phytochemical compounds, essential elements, antioxidant and antimicrobial activities, have been isolated from unutilized parts of fruits found hence making them important to the food, agriculture and pharmaceutical industry (Al-Zoreky,
2009; Dorta et al., 2012; Geraci et al., 2016). Researches have confirmed that there are appreciable amounts of bioactive compounds in waste fruit parts (peels pomaces, seed and fiber) with potential benefits to human health and can also act as fungicides, bactericides and for disease control in agriculture (Al-Zoreky, 2009; Geraci et al., 2016).

The present study utilized a variety of techniques and solvents in the extraction of phytochemicals from the jackfruit parts (the peel, fiber and the core). The extracts from the various solvents were assayed for mineral and various phytochemical compositions. The total phenolic content, flavonoids content, tannins content, DPPH scavenging activity and reducing power were determined using spectrophotometric methods. The mineral analysis was conducted using atomic absorption flame emission spectrometry (AAS). The potential antimicrobial activity of the various solvent extracts was evaluated on xam 
pathogen.

Jackfruit (Artocarpus heterophyllus Lam) is a large and evergreen tree that can produce about 100 to 200 fruits in a year (Prakash et al., 2009). There have been limited studies on unutilized fruit parts of jackfruit. Jackfruit is the largest known edible fruit whose unutilized fruit parts include the peels, fiber and the core are the dominating part of the fruit (accounts for $60 \%$ of the entire fruit). It is clear that the edible pulp and seeds of ripe jackfruits are excellent sources of macronutrients and bioactive compounds. There is however lack of reference available on the chemical composition and antioxidant capacity of the peel, fiber and core of ripe Jackfruits. Most studies on the jackfruit phytochemical, antioxidant properties and mineral analysis have focused on the edible regions (pulp and seeds) (Shanmugapriya, 2011; Sreeletha et al., 2017; Awuor et al., 2018). In addition, lack information on the antibacterial activity of different extracts from peel, fiber and core against bacterial species of agriculture interest. The study of the unutilized parts of the fruit will encourage utilization of the waste parts of the fruits, which will contribute in reducing bio-waste accumulation with the dual aim value addition to jackfruit waste as well as management of pathogenic bacteria in crop plants.

This study purposed to determine the phytochemical composition, mineral profiles and in vitro radical scavenging activities of phenolic compounds of three jackfruit parts (peels, fiber and core) using different extraction techniques and solvents. The knowledge of the phytochemical composition of these fruit parts will help in providing a cost-effective alternative source of phytochemicals and essential minerals. The potential of the polyphenolic extracts of jackfruit fruit parts against Xanthomonas axonopodis pv. manihotis (Xam) bacteria, the causative agent of Cassava Bacterial Blight (CBB) was also evaluated in search of potential biocontrol agents.

\section{Materials and methods}

\subsection{Plant material and sample preparation}

Jackfruits were obtained from farmer's fields in coastal Kenya. Fruits (150 - 180 days old) considered physiologically mature (approximately $10 \mathrm{~kg}$ each) were harvested and used for analysis. The peel, fiber and the core were manually separated and chopped into small pieces. The pieces were cleaned using double distilled water, air-dried at $105^{\circ} \mathrm{C}$ in an oven (Memmert by Vindon Scientific) overnight and ground into fine powder using a grinder (Nutribullet by Homeland Housewares) for subsequent characterization.

\subsection{Solvent extraction of phytochemicals}

The solvent and extraction method was optimized in order to obtain high antioxidant capacity extracts from the peel, fiber and the core of Jackfruit. Fruit peel, fiber and the core were extracted using two different methods (48-hour extraction and homogenization) and two solvents (methanol and distilled water) were tested. For the 48-hour extraction method, the samples (peel, fiber and the core) were incubated with solvents for $48 \mathrm{hrs}$ at $24^{\circ} \mathrm{C}$. A mass of $2.5 \mathrm{~g}$ of each sample was placed into separate conical flasks containing $25 \mathrm{~mL}$ methanol and distilled water supplemented with $5 \%$ acetic acid. The conical flasks containing the samples and the solvents were covered in aluminium foil and incubated at room temperature for $48 \mathrm{hrs}$ as described by Ojwang et al. (2017). On the other hand, for the homogenization method, extraction of phytochemicals was performed using a slight modification of Torti et al. (1993) protocol with slight modifications. A total of $100 \mathrm{mg}$ of the samples were homogenized for longer time $(120 \mathrm{~s})$ at a maximum speed of $3000 \mathrm{rpm}$ instead of $60 \mathrm{~s}$ as indicated in Torti et al. (1993). The falcon tubes were spanned for 15 mins at $10,000 \times g$ at $4^{\circ} \mathrm{C}$. The resultant pellet was then re-suspended in $10 \mathrm{~mL}$ of the test solvents, centrifuged again at $10,000 \times g$ and stored at $4{ }^{\circ} \mathrm{C}$ for subsequent phytochemical analysis.

\subsection{Estimation of phytochemical compounds}

Calorimetric assays described by Abu Bakar et al. (2015) and As et al. (2017) based on the reduction of Folin-Ciocalteu reagent was used to determine the content of phenolic compounds in the various extracts. Absorbance at $725 \mathrm{~nm}$ using UV-VIS spectrophotometer (UVmini-1240 by Shimadzu Corporation) was taken and the results expressed as $\mathrm{mg}$ of gallic acid equivalents per gram of extracts (mg GAE/g). The equations $y=0.0057 x$ +0.4792 for methanol extracts and $y=0.009 x+0.3847$ for water extracts were used for further calculations.

Total flavonoid content (TFC) of crude jackfruit extracts was determined by aluminium chloride colorimetric protocol as described by Kumaran and Karunakaran (2006). Absorbance at $510 \mathrm{~nm}$ using UVVIS spectrophotometer (UVmini-1240 by Shimadzu Corporation) was immediately recorded. The similar method was repeated for rutin standard solution and TFC determined using rutin equivalent (RE) (20 to $100 \mu \mathrm{g} /$ $\mathrm{mL}$ ) calibration curve. The data was expressed as $\mathrm{mg}$ of rutin equivalents $\mathrm{RE} / \mathrm{g}$ of extract. The equations $\mathrm{y}=$ $0.0004 x+0.0573$ for methanol extracts and $y=0.0015 x$ - 0.0094 for water extracts were used to compare the results.

The amount of tannin in the sample was estimated 
using Folin-Ciocalteu method. A total of $100 \mu \mathrm{L}$ of extracts was added to $0.25 \mathrm{~mL}$ Folin-Ciocalteu reagent, incubated for 5 mins before the addition of $1.25 \mathrm{~mL}$ of the sodium carbonate solution, mixed well and the absorbance read against a blank at $725 \mathrm{~nm}$ after 40 mins. The total tannin content was calculated as GAE with reference to a standard curve prepared based on standards of Gallic acid concentration (0 to $100 \mu \mathrm{g} / \mathrm{mL})$. The equations $\mathrm{y}=0.0089 \mathrm{x}+0.1312$ for methanol extracts and $y=0.0086 x+0.136$ for water extracts were used to calculate the values.

\subsection{Determination of DPPH radical scavenging activity}

The protocol was based on 2,2-diphenyl-1picrylhydrazyl (DPPH) radical scavenging activity by Adjimani and Asare (2015) with some modifications was used to determine the antioxidant activity of the extracts. A standard (ascorbic acid) and a blank containing all the test reagents except the test extract were used. Calculations were based on the following equation:

Scavenging activity $(\%)=\frac{\text { Absorbance of Control }- \text { Absorbance of Sample }}{\text { Absorbance of Control }} \times 100$

\subsection{Reducing power of the extracts}

The method described by Sylvie et al. (2014) was used to estimate the reducing power of the extracts. One $\mathrm{mL}$ of extract was added to a mixture containing $2.5 \mathrm{~mL}$, of $0.2 \mathrm{~mol} / \mathrm{L}$ phosphate buffer (pH 6.6) and $2.5 \mathrm{~mL},(1 \%)$ potassium ferricyanide. The mixture was kept in an oven for 20 mins at $50^{\circ} \mathrm{C}$ before the addition of $2.5 \mathrm{~mL}$ of $10 \%$ Trichloroacetic acid (TCA) and then centrifuged at $3000 \mathrm{rpm}$ for $10 \mathrm{mins}$. The upper phase $(2.5 \mathrm{~mL})$ of the solution was mixed with an equal volume of distilled water and $0.5 \mathrm{~mL}, 0.1 \%$ ferric chloride $\left(\mathrm{FeCl}_{3}\right)$. The absorbance of the mixture was read at $700 \mathrm{~nm}$ against a blank containing all the test reagents except the extract.

\subsection{Mineral analysis}

These were analyzed by atomic absorption flame emission spectrometry (AAS) according to Osarumwense et al. (2013) but using Varian SpectrAA10 machine instead of a bulk Scientific VGP 210 model of AAS. A wet digestion technique was used to convert solids to liquids. One $\mathrm{g}$ each of the finely powdered sample was treated with $60 \% \mathrm{HNO}_{3}$ in a beaker for digestion and placed in a hot plate in a fume cupboard. The mixture was allowed to boil for 30 mins where brown fumes were released with a resultant clear liquid. The mineralized samples were transferred into $50 \mathrm{~mL}$ volumetric flasks and de-ionized distilled water used to adjust volumes to the mark.

For AAS, an atomic absorption flame emission spectrophotometer (Varian SpectrAA-10) with an air- acetylene flame was used. The wavelengths were set to $422.7 \mathrm{~nm}$ for calcium (Ca), $279.5 \mathrm{~nm}$ for manganese $(\mathrm{Mn}), 248.3 \mathrm{~nm}$ for iron (Fe), $213.9 \mathrm{~nm}$ for zinc $(\mathrm{Zn})$, $589.0 \mathrm{~nm}$ for Sodium $(\mathrm{Na}), 766.8 \mathrm{~nm}$ for potassium $(\mathrm{K})$, $324.8 \mathrm{~nm}$ for copper $(\mathrm{Cu})$ and $285.2 \mathrm{~nm}$ for Magnesium $(\mathrm{Mg})$ determination were used. Stock solutions (1000 ppm) of $\mathrm{Ca}, \mathrm{Mn}, \mathrm{Fe}, \mathrm{Cu}, \mathrm{Na}, \mathrm{K}, \mathrm{Mg}$ and $\mathrm{Zn}$ were used to prepare working standard solutions with at least 3 concentrations (1 ppm, $5 \mathrm{ppm}$ and10 ppm) within the analytical range.

\subsection{Determination of antimicrobial activities}

Xanthomonas axonopodis pv. manihotis (Xam) is a pathogenic bacterium that causes bacterial blight disease in cassava. A few infected leaf samples from plants of cassava cultivar TME14 were collected from western Kenya. The protocol by Chege et al. (2017) was used in the isolation of the pathogen. A total of $5 \mathrm{~mL}$ of yeast peptone glucose (YPG) media was sterilized, after which cephalexin and cycloheximide antibiotics at $150 \mathrm{mg} / \mathrm{L}$ and $50 \mathrm{mg} / \mathrm{L}$ respectively were added. Small pieces of leaf tissues were cut into sterile $15 \mathrm{~mL}$ falcon tubes containing the selective media and incubated at $28^{\circ} \mathrm{C}$ for $48 \mathrm{hrs}$. The resultant bacterial suspension was serially diluted to $10^{3}$ and $50 \mu \mathrm{L}$ of each dilution plated on YPGA medium supplemented with cephalexin and cycloheximide antibiotics and incubated for 48 hours at $28^{\circ} \mathrm{C}$. Single colonies were picked, purified and used for antimicrobial test.

Antibacterial sensitivity assay was done using the disc diffusion method highlighted in As et al. (2017). Extracts obtained from the various powdered jackfruit wastes using different solvents were tested on Xam pathogen. The Xam bacteria were cultured for $48 \mathrm{hrs}$ and then evenly spread on Mueller Hinton agar plates. Sterile discs of Whatman paper ( $6 \mathrm{~mm}$ in diameter) were dipped in extract solution and placed in the inoculated agar plate before incubating at $28^{\circ} \mathrm{C}$ for $48 \mathrm{hrs}$ and eventually measuring the zones of inhibition. Three replicates were used and the experiment was repeated twice.

\subsection{Statistical analysis}

The mean values of the data obtained were determined and analyzed using one-way ANOVA at $\mathrm{P}<0.05$. The data was analyzed using Microsoft Excel 2011 data analysis tool and StatPlus statistical software. The relationship between phenolic, flavonoid, tannins, DPPH and antioxidant activity were determined using a correlation matrix. 


\section{Results and discussion}

3.1 Effect of solvent and extraction technique on the content of phytochemicals

The total phenolic content of peels, fiber and the core were determined spectrophotometrically after extraction with methanol and with distilled water. In general, the highest phenolic content was found in the fiber followed by peels and then the core at $23.28 \mathrm{mg} / \mathrm{g}$, $17.07-6.38 \mathrm{mg} / \mathrm{g}$ and $15.68-8.37 \mathrm{mg} / \mathrm{g}$, respectively (Table 1). The differences in total phenolic content extracted using different solvents with $100 \%$ methanolic extract (48 hrs) having the highest composition, followed by the $70 \%$ methanolic extract was significant $(\mathrm{P}<0.05)$. The lowest phenolic content was recorded from the distilled water extract for both $48 \mathrm{hrs}$ incubation and homogenization methods. Previously used organic solvents for extraction of phenolic compounds from plants include methanol, ethanol acetone and ethyl acetate (Lafka et al., 2007; Alothman et al., 2009). It has been shown that phenolic content differs with solvent polarities; pure methanol and acetone were found to be better solvents than water (Addai et al., 2013).

The flavonoid contents of peel, fiber and the core were as shown in Table 1. Fibers had the highest flavonoid content in samples that were incubated with a solvent for 48 hours, while peels showed the highest flavonoid content in the samples that were homogenized and centrifuged. There was a significant variation $(\mathrm{P}<0.05)$ in flavonoid compounds extracted using different solvents. The methanolic extract (48 hours incubation) gave the highest composition in all parts. The fiber had the highest flavonoid content in the 48 hours extraction in both methanol and distilled water, while the peels had the highest composition in homogenized extracts. The highest levels of flavonoids in peripheral tissues are consistent with other studies. Banana peels were found to have higher flavonoid content than the pulp (Fatemeh et al., 2012)

The tannin content from unutilized parts of jackfruit was depended on the extraction method used (Table 1). Homogenization method was the best method for extraction of tannins for all samples while the best extraction solvent for tannins was distilled water. The fiber consistently gave high values in all extraction methods and solvents. There was a significant variation $(\mathrm{P}<0.05)$ in the extraction solvents used with distilled water and $70 \%$ methanol recording high values compared to the methanol. This could be attributed to the fact that tannin compounds are soluble in water (Mena et al., 2015)

The variation in the phytochemical composition of samples extracted with methanol and distilled water with 48 hours incubation as well as with the homogenization method was significant $(\mathrm{P}<0.05)$. Flavonoids had the highest composition in the methanol extraction, followed

Table 1. Concentration of phytochemical compounds extracted from fruit peels, fiber and core extracts of Jackfruit using different solvents and extraction methods

\begin{tabular}{|c|c|c|c|c|c|}
\hline \multirow{2}{*}{ Method of Extraction } & \multirow{2}{*}{ Tissue } & \multirow{2}{*}{ Solvent } & \multicolumn{3}{|c|}{ Phytochemicals } \\
\hline & & & Phenolics & Flavonoids & Tannins \\
\hline \multirow{9}{*}{48 hrs Extraction } & \multirow{2}{*}{ Peels } & Meth & $17.07 \pm 5.16$ & $28.55 \pm 12.42$ & $5.83 \pm 2.83$ \\
\hline & & $\mathrm{dH}_{2} \mathrm{O}$ & $10.19 \pm 2.32$ & $3.11 \pm 0.79$ & $4.9 \pm 0.14$ \\
\hline & P-values & & 0.638273 & 0.000727 & 0.308509 \\
\hline & \multirow{2}{*}{ Fiber } & Meth & $23.28 \pm 4.73$ & $35.4 \pm 9.53$ & $8.73 \pm 3.58$ \\
\hline & & $\mathrm{dH}_{2} \mathrm{O}$ & $15.15 \pm 4.47$ & $3.67 \pm 3.18$ & $7.76 \pm 4.20$ \\
\hline & P-values & & 0.798075 & 0.014103 & 0.162447 \\
\hline & \multirow{2}{*}{ Core } & Meth & $15.68 \pm 3.74$ & $24.15 \pm 20.99$ & $4.61 \pm 2.64$ \\
\hline & & $\mathrm{dH}_{2} \mathrm{O}$ & $14.12 \pm 5.41$ & $2.66 \pm 1.62$ & $5.37 \pm 2.01$ \\
\hline & P-values & & 0.114262 & 0.014047 & 0.661028 \\
\hline \multirow{9}{*}{ Homogenization } & \multirow{2}{*}{ Peels } & Meth & $6.38 \pm 2.80$ & $22.17 \pm 26.08$ & $5.96 \pm 2.07$ \\
\hline & & $\mathrm{dH}_{2} \mathrm{O}$ & $7.7 \pm 3.73$ & $25.25 \pm 4.55$ & $10.82 \pm 2.63$ \\
\hline & P-values & & 0.015424 & 0.006625 & 0.011504 \\
\hline & \multirow{2}{*}{ Fiber } & Meth & $13.91 \pm 12.66$ & $14.72 \pm 9.81$ & $12.27 \pm 5.55$ \\
\hline & & $\mathrm{dH}_{2} \mathrm{O}$ & $11.92 \pm 4.24$ & $13.59 \pm 1.15$ & $10.39 \pm 4.10$ \\
\hline & P-values & & 0.655119 & 0.529461 & 0.922842 \\
\hline & \multirow{2}{*}{ Core } & Meth & $13.91 \pm 1.25$ & $12.27 \pm 19.91$ & $9.69 \pm 6.94$ \\
\hline & & $\mathrm{dH}_{2} \mathrm{O}$ & $8.37 \pm 2.81$ & $17.16 \pm 2.95$ & $10.52 \pm 1.05$ \\
\hline & P-values & & 0.057748 & 0.065747 & 0.656972 \\
\hline
\end{tabular}

Values are means \pm standard deviation of triplicate analysis. P-values on the table indicate difference in solvent extraction efficiency of the various phytochemicals. 
by phenolics and lastly tannins (Table 1). Among the fruit parts, fibers showed the highest phytochemical composition, followed by peels and then the core (Table 1). The extraction with distilled water gave the highest composition for the phenolic compounds and the least for the flavonoids. The highest levels of tannins were extracted in distilled water for 48 hours and there was no variation in the level of tannins between the different parts (Table 1).

\subsection{Effect of solvent and extraction methods on the antioxidant activities}

There was a significant variation $(\mathrm{P}<0.05)$ in $\mathrm{DPPH}$ scavenging activity of the extracts. The highest DPPH scavenging activity was $50.78 \pm 3.81 \%$ for peels using $\mathrm{H}_{2} \mathrm{O}$ and centrifugation, followed by $61.51 \pm 29.90 \%$ for fiber using $\mathrm{H}_{2} \mathrm{O}$ for $48 \mathrm{hrs}$ incubation and $51.06 \pm 33.39 \%$ for core using $\mathrm{H}_{2} \mathrm{O}$ and centrifugation method. Water extracted the highest antioxidants from all the parts but the levels varied with respect to the extraction method used (Table 2).

Table 2. Iron reducing power of extracts from Jackfruit peels, fiber and the core

\begin{tabular}{lccc}
\hline Extraction technique and & \multicolumn{3}{c}{ Ferric reducing power $(\mathrm{mg} / \mathrm{mL})$} \\
\cline { 2 - 4 } solvent used & Peels & Fiber & Core \\
\hline $\begin{array}{l}48 \text { hrs extraction, } \\
\text { distilled } \mathrm{H}_{2} \mathrm{O}\end{array}$ & $3.59 \pm 0.15^{\mathrm{a}}$ & $6.12 \pm 2.80^{\mathrm{e}}$ & $5.09 \pm 0.14^{\mathrm{i}}$ \\
$\begin{array}{l}\mathrm{Homogenization}, \text { distilled } \\
\mathrm{H}_{2} \mathrm{O}\end{array}$ & $2.49 \pm 0.34^{\mathrm{b}}$ & $2.89 \pm 0.91^{\mathrm{f}}$ & $2.63 \pm 1.17^{\mathrm{b}}$ \\
$\begin{array}{l}48 \text { hrs extraction, } \\
\text { methanol }\end{array}$ & $6.69 \pm 4.07^{\mathrm{c}}$ & $7.94 \pm 4.56^{\mathrm{g}}$ & $5.20 \pm 1.33^{\mathrm{j}}$ \\
$\begin{array}{l}\text { Homogenization, 70\% } \\
\text { methanol }\end{array}$ & $2.11 \pm 0.36^{\mathrm{d}}$ & $2.46 \pm 0.96^{\mathrm{h}}$ & $2.10 \pm 0.49^{\mathrm{d}}$ \\
\hline
\end{tabular}

Values are means \pm standard deviation of triplicate analysis. Values in the same column with different superscript letters are significantly different $(\mathrm{P}<0.05)$.

The variation in the ferric reducing antioxidant power of the extracts from different unutilized parts of jackfruit (Table 2) was significant $(\mathrm{P}<0.05)$. The extracts from the fiber consistently gave the highest iron reducing power in all the extracting solvents and extraction techniques used (Table 2). The variation in Iron concentration from one tissue to the other is an indication of the difference in its utilization by tissues. These results confirm that the presence of high levels of flavonoids does not always correspond to high antioxidant properties in plants (Teixeira et al., 2017).

\subsection{Correlating phytochemical contents to total antioxidant capacity}

There was a positive correlation between DPPH scavenging activity and the phenolic and tannin composition (Table 3 ) of the jackfruit parts studied. This was also the case between polyphenol levels and reducing power activity. However, there was a negative correlation in the flavonoids extracted from the same jackfruit parts studied (Table 3).

\subsubsection{Mineral profile}

Mineral analysis of Jackfruit peels, fiber and the core showed the presence of high levels of essential elements within the waste parts of the fruit. There was a significant variation $(\mathrm{P}<0.05)$ in $\mathrm{K}, \mathrm{Na}$ and $\mathrm{Ca}$ levels present in the parts studied. Potassium accounted for the major element followed by $\mathrm{Ca}$ while $\mathrm{Na}$ levels were the least (Table 4). This is consistent with other studies where the peels of watermelon, mango, pomegranate, banana, apple and pineapple were found to be rich in essential minerals such as calcium, zinc, iron and manganese (Romelle et al., 2017).

\subsubsection{Antimicrobial activity}

Acetone and ethyl acetate extracts had antibacterial activity against Xam pathogen (Table 5). For the acetone extracts, the peels gave the highest inhibition followed by the fiber while the core gave the least. On the other hand, ethyl acetate extracts from jackfruit fiber and the core gave the highest and least antibacterial activities respectively. In general, Ethyl acetate was a better solvent than the aqueous $(50 \%)$ acetone. These findings differ from those on Pisang $A b u$ where $90 \%$ and $70 \%$ acetone gave the highest levels of phenolic compounds compared to other solvents (Toh et al., 2016).

\section{Discussion}

The unutilised parts of the fruits have been found to have phytochemical compounds, essential elements, antioxidant and antimicrobial activities, which makes

Table 3. Correlation matrix of phytochemical composition and antioxidant activity of extracts of Jackfruit bio-waste

\begin{tabular}{cccccc}
\hline & Phenolics & Flavonoids & Tannins & DPPH & Reducing power \\
\hline Phenolics & 1 & 0.145 & 0.99 & 0.996 & 0.999 \\
Flavonoids & -0.145 & 1 & 0.281 & 0.053 & 0.095 \\
Tannins & 0.99 & -0.281 & 1 & 0.973 & 0.982 \\
DPPH & 0.996 & -0.053 & 0.973 & 1 & 0.999 \\
Reducing power & 0.999 & -0.095 & 0.982 & 0.999 & 1 \\
\hline
\end{tabular}

Linear regression analysis between estimated antioxidant activities, free radical scavenging activities and iron reducing power with total phenolic, flavonoid and condensed tannins. 
Table 4. Mineral composition of extracts from jackfruit peels, fiber and the core

\begin{tabular}{cccc}
\hline \multirow{2}{*}{ Parameters } & \multicolumn{3}{c}{ Mineral content $(\mathrm{mg} / \mathrm{g} \mathrm{DW})$} \\
\cline { 2 - 4 } & Peels $(\mathrm{mg} / \mathrm{g})$ & Fiber $(\mathrm{mg} / \mathrm{g})$ & Core $(\mathrm{mg} / \mathrm{g})$ \\
\hline Potassium $(\mathrm{K})$ & $22.8 \pm 9.400$ & $31.07 \pm 17.502$ & $24.15 \pm 8.105$ \\
Sodium $(\mathrm{Na})$ & $0.47 \pm 0.087$ & $0.48 \pm 0.091$ & $0.43 \pm 0.079$ \\
Calcium $(\mathrm{Ca})$ & $4.9 \pm 1.929$ & $7.32 \pm 4.099$ & $6.94 \pm 2.074$ \\
Magnesium $(\mathrm{Mg})$ & $1.456 \pm 1.291$ & $1.24 \pm 0.421$ & $1.322 \pm 0.752$ \\
Zinc $(\mathrm{Zn})$ & $1.44 \pm 1.038$ & $0.98 \pm 0.044$ & $1.9 \pm 0.408$ \\
Copper $(\mathrm{Cu})$ & $0.018 \pm 0.017$ & $0.005 \pm 0.005$ & $0.009 \pm 0.011$ \\
Manganese $(\mathrm{Mn})$ & $0.015 \pm 0.0072$ & $0.01 \pm 0.0025$ & $0.011 \pm 0.004$ \\
Ferrous $(\mathrm{Fe})$ & $0.112 \pm 0.060 *$ & $0.088 \pm 0.133$ & $0.051 \pm 0.023^{*}$ \\
\hline
\end{tabular}

Values are means \pm standard deviation of triplicate analysis. The difference between values with an asterisk $(*)$ is significant $(\mathrm{P}$ $<0.05)$.

Table 5. Antibacterial activity of extracts from the peel, fiber and core of the jackfruit against Xanthomonas axonopodis pv. manihotis (Xam)

\begin{tabular}{cccc}
\hline \multirow{2}{*}{ Solvent used } & \multicolumn{3}{c}{ Inhibition zone diameter $(\mathrm{mm})$} \\
\cline { 2 - 4 } & Peels & Fiber & Core \\
\hline Acetone & $4.39 \pm 1.35$ & $3.56 \pm 2.17$ & $3.08 \pm 2.28$ \\
Ethyl acetate & $6.50 \pm 1.62$ & $7.10 \pm 2.13^{*}$ & $5.06 \pm 2.64^{*}$ \\
P values & 0.0428925 & 0.000522 & 0.093637 \\
\hline
\end{tabular}

Values are means \pm standard deviation of triplicate analysis. The difference between values with an asterisk $(*)$ is significant $(\mathrm{P}<0.05)$ while the $\mathrm{P}$-values on the table indicate the difference in activity of extracts from the two solvents used in each tissue.

them important to the food and pharmaceutical industry (Al-Zoreky 2009; Dorta et al., 2012; Geraci et al., 2017). In the present study, considerable amounts of phytochemical compounds with remarkable antioxidant and antimicrobial activities were obtained from peel, fiber and the core of Jackfruit. In addition, the study confirmed that the extracting solvent and extraction method are critical factors in the extraction of phytochemicals from bio-waste. This agrees with the study by Do et al. (2014) who also found out that the extraction of phytochemicals varies with the type of solvent used and extraction technique applied.

The chemical composition of unutilized fruit parts of jackfruit is essential in order to establish a potential relationship and understanding of their role in different valuable biological activities. There was no significant variation in total phenolic contents (TPC) from the different unutilized parts of the fruit. This could be attributed to the fact that all the studied sections are parts of the entire fruit. Metabolites are known to diffuse from one part of the fruit to another, which makes the TPC levels almost the same (Etxeberria et al., 2012). The solubility of polyphenolic compounds in the extracting solvent and the extraction method used determines the ease of their recovery from plant materials. The polarity of the solvent will also play a crucial role in raising the solubility of phenolic acids (Do et al., 2014). In the present study, methanolic extracts had the highest composition of phenolic compounds in comparison to distilled water extracts and this could be attributed to the amphiphilic nature of methanol. Another explanation for the polyphenols in water extracts could be due to the degradation of polyphenols in aqueous extracts (observed as brown color the extracts) by the enzyme polyphenol oxidase. This enzyme is inactive in methanol as reported by Gonźalez-Montelongo et al. (2010). Phenolic compounds have varying degrees of polarity and some may not dissolve in a $100 \%$ polar solvent like water (Boeing et al., 2014). Studies have also shown that there are quantifiable water-soluble polyphenols present in plants (Kawakami et al., 2010).

There was a significant variation in the levels of flavonoids extracted using different solvents. Methanol extraction gave the highest total flavonoid content (TFC) in all fruit parts and in all techniques compared to water. This is because the concentration of extracted flavonoid compounds extracted from plant material is influenced by the polarity of solvents used (Tambe and Bhambar, 2014). Naturally occurring flavonoids such as rutin, have low solubility in water (Lipkovska et al., 2014). Homogenization with water and methanol solvents was found to be the best technique for extraction of flavonoid compounds. This is because homogenization results in the grinding of the plant material to a fine powder with resultant disruption of cell walls hence increased extraction surface area (Das et al., 2010).

There was no significant variation in total tannin content (TTC) $(P>0.05)$ in the different parts as there is an exchange and free movement of tannins between the three interconnected parts of the fruit when the need arises (Shitan, 2016). There was however a significant variation $(\mathrm{P}<0.05)$ in TTC extracted using different solvents. Distilled water extracts had the highest composition of phenolic compounds compared to methanolic extracts. Previous research by Mena et al. 
(2015) showed that most tannin compounds are soluble in water. However, our results contradict reports by Baldosano et al. (2015) who indicated that water proved to be an ineffective solvent for the extraction of tannins due to the formation of insoluble complexes with proteins. Results from the current study could be as a result of low protein content in the parts studied as was shown in other previous studies which reported lower content of proteins in Jackfruit (Swami et al., 2012; Madruga et al., 2014).

The findings of the present study are consistent with those of Boeing et al. (2014), that showed methanol as a better solvent in the extraction of phenolic compounds in berries. Total phenolic content differs with solvent polarities (Addai et al., 2013). A similar scenario was also observed in the current study. Pure methanol and acetone were found to be better solvents than water (Addai et al., 2013). A study by Alothman et al. (2009), revealed that the type of solvent used had an effect on the quantity of phenolic compounds extracted from plants (Alothman et al., 2009). The current results were also consistent with those of Iloki-Assanga et al. (2015), that indicated that the levels of phytochemicals in Bucida buceras $L$. and Phoradendron californicum was affected by the extraction solvent used.

The assay on DPPH scavenging activity is based on the donation of hydrogen by antioxidant groups like phenolics, flavonoids and tannins (Rohman et al., 2010). The fiber samples had an average of $58 \%$ scavenging activity, $10 \%$ higher than the peels and the core, which were equal at about $48 \%$. The results also showed that antioxidant activity is not very sensitive to extraction solvents as the values were mostly above $50 \%$ but higher radical scavenging compounds were from distilled water extracts. There variation in reducing power depending on the technique and solvent used was significant $(\mathrm{P}<0.05)$. Incubation of sample with solvent for 48 hours was a better technique as compared to homogenization for the extraction of compounds with reducing power, while methanol was a better solvent as compared to water. Fiber samples consistently had the greatest iron reducing power in all the solvents and techniques.

The correlation between DPPH scavenging activity and the composition of phenolic and tannin in the Jackfruit parts studied were positive. This was also the case in a study by Almeida et al. (2011), which focused on free radical scavenging activity of fruit samples. There was however no correlation between flavonoid and radical scavenging activity just like it was in the study by Bilušić et al. (2007). The results generally indicate the presence of high antioxidant activity in the extracts of the peels, fiber and the core of jackfruit.
Hence, the fruit is a potential source of natural antioxidants. Polyphenol levels positively correlated with reducing power activity while flavonoids extracted from the peels, fiber and core parts of the Jackfruits studied negatively correlated. These results contrast with other studies which showed a positive correlation between flavonoids extracted and their DPPH scavenging activity as well as iron reducing power (Rohman et al., 2010; Abu Bakar et al., 2015; Ojwang et al., 2017). These results show that the presence of high levels of flavonoids does not always correspond to high antioxidant properties in plants as these metabolites have a wide variety of activities (Teixeira et al., 2017).

In the current study, mineral analysis of jackfruit peels, fiber and core showed that there are high levels of essential elements present within the waste parts of the fruit. In general, most fruits contain high levels of potassium (Julian-Loaeza et al., 2011). The Jackfruit biowaste contained high levels of potassium followed by calcium and then sodium. Similar finding was reported by Akinmutimi, (2006) and Swami et al. (2012). Consumption of food with high potassium/calcium to sodium levels have been shown to mitigate the risk of hypertension (Perez and Chang, 2014). The elements Sodium and potassium in combination, maintain optimal acid-base balance and nerve impulses transmission in the body (Adumanya et al., 2015). The study also showed the presence of trace elements namely zinc and magnesium in high quantities. These elements are important in plants for their normal growth and development. It is important to note that the mineral Zinc, is essential in the functioning of enzymes involved in carbohydrate, lipid and protein metabolism of zinc is also an essential mineral for (Julian-Loaeza et al., 2011; Osarumwense et al., 2013). There were also low amounts of iron, copper and manganese, which are essential for proper plant daily functions. Jackfruit peels, fiber and core are a, therefore, a potential source of essential minerals and their use in biofortification of food could lead to improved health.

The antibacterial properties of different extracts of peel, fiber and core were assayed against Xam and measured inhibition zones exerted by each extract towards the bacteria. Both acetone and ethyl acetate extracts showed efficacy in antibacterial activity against Xam. The activity was highest in the peels and lowest in the core. This could be attributed to the fact that the peels form the protective outer layer of the fruit and it is more exposed to microbial pathogens compared to the inner parts of the fruit and hence the antimicrobial compounds are more likely to be in the peels. Furthermore, antimicrobial activity of polyphenol and flavonoids have demonstrated by a number of studies (Swami et al., 
2012; Sylvie et al., 2014) and therefore the same can be inferred for the antimicrobial activity of extracts from jackfruit unutilized parts. The broad-spectrum antibacterial activities of phenolic compounds are attributed to the configuration of their structure. The hydroxyl group content and degree of polymerization contribute to their antimicrobial activities (Daglia, 2012). Ethyl acetate extracts were the most significantly effective solvent than aqueous acetone against Xam bacteria. These results agree with those by As et al. (2017) and Swami et al. (2012) which showed that the edible parts of Jackfruit have antimicrobial activity.

The high potential revealed by peel, fiber and core extracts of jackfruit to inhibit a cassava bacterial pathogen, highlights the promising potential application for this bio-waste. The high content of polyphenols in the studied parts of the fruit may be attributed to their strong antibacterial activity against the bacteria tested. These data suggest that peels, fiber and core of Jackfruits contain potential inhibitors of plant pathogenic bacteria and would be a good candidate for the future development of a bio-bactericide for agricultural application.

\section{Conclusion}

The unutilized parts (peels, fire and the core) of jackfruit are all good natural sources of phytochemicals such as phenolics, flavonoids and tannins. That the solvent used and the extraction technique affects the levels of phytochemicals extracted and hence their functional properties (antioxidant and antimicrobial) to various magnitudes. Phenolic and flavonoid contents were highest in methanol extracts and 48 hours incubation, whereas the highest content of tannins was obtained with distilled water and homogenization. The peels, fiber and the core are all good sources of essential minerals such as $\mathrm{Fe}, \mathrm{Ca}, \mathrm{K}, \mathrm{Na}$ and $\mathrm{Mg}$ amongst others. The extracts of unutilized parts of jackfruit have potential antioxidant and antimicrobial properties that vary depending on the extraction solvent used. These results have therefore established that peels, fiber and the core of jackfruits exhibited high antioxidant and antibacterial activities in vitro.

\section{Conflict of Interest}

The authors declare no conflict of interest.

\section{Acknowledgments}

The authors would like to offer thanks to the Department of Biochemistry, University of Nairobi for providing the research materials and facilities. The Ministry of Mining, Kenya is also acknowledged for facilitating mineral analysis in their laboratory facilities.

\section{References}

Abu Bakar, M., Abdul Karim, F., Perisamy, E., Bakar, M.F.A., Karim, F.A. and Perisamy, E. (2015). Comparison of phytochemicals and antioxidant properties of different fruit parts of selected Artocarpus Species from Sabah, Malaysia. Sains Malaysiana, 44(3), 355-363. https:// doi.org/10.17576/jsm-2015-4403-06

Addai, Z.R., Abdullah, A. and Mutalib, S.A. (2013). Effect of extraction solvents on the phenolic content and antioxidant properties of two papaya cultivars. Journal of Medicinal Plant Research, 7, 3354-3359

Adjimani, J.P. and Asare, P. (2015). Antioxidant and free radical scavenging activity of iron chelators. Toxicology Reports, 2, 721-728. https:// doi.org/10.1016/j.toxrep.2015.04.005

Adumanya, O.C.U., Obiloma, A.A. and Essien, E.B. (2015). Proximate, vitamins and mineral composition of Salacia senegalensis Lam (DC) leaves. Open Journal of Research, 2, 92-105.

Akinmutimi A.H. (2006). Nutritive Value of Raw and Processed Jack Fruit Seeds (Artocarpus heterophyllus): Chemical Analysis. Agriculture Journal, 1(4), 266-271.

Al-Zoreky, N.S. (2009). Antimicrobial activity of pomegranate (Punica granatum L.) fruit peels. International Journal of Food Microbiology, 134(3), 244-248.

j.ijfoodmicro.2009.07.002

Almeida, M.M.B., de Sousa, P.H.M., Arriaga, Â.M.C., do Prado, G.M., Magalhães, C.E.C., Maia, G.A. and de Lemos, T.L.G. (2011). Bioactive compounds and antioxidant activity of fresh exotic fruits from northeastern Brazil. Food Research International, 44 (7), 2155-2159. https://doi.org/10.1016/ j.foodres.2011.03.051

Alothman, M., Bhat, R. and Karim, A.A. (2009). Antioxidant capacity and phenolic content of selected tropical fruits from Malaysia, extracted with different solvents. Food Chemistry, 115(3), 785-788. https://doi.org/10.1016/j.foodchem.2008.12.005

Asquieri, E.R., Rabelo, A.M.S. and Silva, A.G.M. (2008). Fermented jackfruit: study on its physicochemical and sensorial characteristics. Food Science and Technology, 28, 881-887. https:// doi.org/10.1590/S0101-20612008000400018

Awuor Ojwang, R., Muge, E.K., Mbatia, B.N., Mwanza, B.K., Ogoyi, D.O. and Moalla Rekik, D. (2018). Compositional, Elemental, Phytochemical and Antioxidant Characterization of Jackfruit (Artocarpus heterophyllus) Pulps and Seeds from 
Selected Regions in Kenya and Uganda, 23(3), 1-12. https://doi.org/10.9734/EJMP/2018/40967

Baldosano, H.Y., Beatriz, M., Castillo, M.G., Danica, C., Elloran, H. and Bacani, F.T. (2015). Effect of particle size, solvent and extraction time on tannin extract from Spondias purpurea Bark through soxhlet extraction presented at the DLSU Research Congress 2015, March 2 - 4, 2015. Manila, Phillipines: De La Salle University

Bilušić Vundać, V., Brantner, A.H. and Plazibat, M. (2007). Content of polyphenolic constituents and antioxidant activity of some Stachys taxa. Food Chemistry, 104(3), 1277-1281. https:// doi.org/10.1016/j.foodchem.2007.01.036

Boeing, J.S., Barizão, E.O., E Silva, B.C., Montanher, P.F., de Cinque Almeida, V. and Visentainer, J.V. (2014). Evaluation of solvent effect on the extraction of phenolic compounds and antioxidant capacities from the berries: application of principal component analysis. Chemistry Central Journal, 8, 48. https:// doi.org/10.1186/s13065-014-0048-1

Chege, M.N., Wamunyokoli, F., Kamau, J. and Nyaboga, E.N. (2017). Phenotypic and genotypic diversity of Xanthomonas axonopodis pv. manihotis causing bacterial blight disease of cassava in Kenya. Journal of Applied Biology and Biotechnology, 5(2), 38-44.

Daglia, M. (2012). Polyphenols as antimicrobial agents. Current Opinion in Biotechnology, 23(2), 174-181. https://doi.org/10.1016/j.copbio.2011.08.007

Das, K., Tiwari, R.K.S. and Shrivastava, D.K. (2010). Techniques for evaluation of medicinal plant products as antimicrobial agent: Current methods and future trends. Journal of Medicinal Plants Research, 4(2), 104-111.

Do, Q.D., Angkawijaya, A.E., Tran-Nguyen, P.L., Huynh, L.H., Soetaredjo, F.E., Ismadji, S. and Ju, Y.H. (2014). Effect of extraction solvent on total phenol content, total flavonoid content and antioxidant activity of Limnophila aromatica. Journal of Food and Drug Analysis, 22(3), 296-302. https://doi.org/10.1016/j.jfda.2013.11.001

Dorta, E., Lobo, M.G. and Gonzalez, M. (2012). Reutilization of mango byproducts: Study of the effect of extraction solvent and temperature on their antioxidant properties. Journal of Food Science, 77 (1), $\quad$ 80-88. https://doi.org/10.1111/j.17503841.2011.02477.x

Etxeberria, E., Pozueta-Romero, J. and Gonzalez, P. (2012). In and out of the plant storage vacuole. Plant Science, 190, 52-61. https://doi.org/10.1016/ j.plantsci.2012.03.010

Fatemeh, S.R., Saifullah, R., Abbas, F.M.A. and Azhar, M.E. (2012). Total phenolics, flavonoids and antioxidant activity of banana pulp and peel flours: influence of variety and stage of ripeness. International Food Research Journal, 19(3), 10411046.

Feumba, D.R., Ashwini, R.P. and Ragu S.M. (2016). Chemical composition of some selected fruit peels. European Journal of Food Science and Technology, $4(4), 12-21$.

Geraci, A., Di Stefano, V., Di Martino, E., Schillaci, D. and Schicchi, R. (2016). Essential oil components of orange peels and antimicrobial activity. Natural Product Research, 31(6), 653-659. https:// doi.org/10.1080/14786419.2016.1219860

Gonźalez-Montelongo, R., Lobo M.G. and Gonźalez, M. (2010). Antioxidant activity in banana peel extracts: testing extraction conditions and related bioactive compounds. Food Chemistry, 119, 1030-1039. https://doi.org/10.1016/j.foodchem.2009.08.012

Hoornweg, D., Bhada-Tata. P. and Kennedy, C. (2013) Environment: Waste production must peak this century. Nature, 502, 615-617. https:// doi.org/10.1038/502615a

Iloki-Assanga, S.B., Lewis-Luján, L.M., Lara-Espinoza, C.L., Gil-Salido, A.A., Fernandez-Angulo, D., Rubio -Pino, J.L. and Haines, D.D. (2015). Solvent effects on phytochemical constituent profiles and antioxidant activities, using four different extraction formulations for analysis of Bucida buceras L. and Phoradendron californicum. BMC Research Notes, 8, 396. https://doi.org/10.1186/s13104-015-1388-1

Julian-Loaeza, A.P., Santos-Sanchez, N.E., ValadezBlanco, R., Sanchez-Guzman, B.S. and SalasCoronado, R. (2011). Chemical composition, color, and antioxidant activity of three varieties of Annona diversifolia Safford fruits. Industrial Crops and Products, 34, 1262-1268. https://doi.org/10.1016/ j.indcrop.2010.06.012

Kawakami, K., Aketa, S., Nakanami, M., Iizuka, S. and Hirayama, M. (2010). Major water-soluble polyphenols, proanthocyanidins, in leaves of Persimmon (Diospyros kaki) and their amylase inhibitory activity. Bioscience, Biotechnology and Biochemistry, 74(7), 1380 - $1385 . \quad \mathrm{https} / / /$ doi.org/10.1271/bbb.100056

Kumaran, A. and Karunakaran, J. (2006). In vitro antioxidant activities of methanol extracts of five Phyllanthus species from India. LWT-Food Science and Technology, 40(2), 344-352. https:// doi.org/10.1016/j.lwt.2005.09.011

Lafka, T.I., Sinanoglou, V. and Lazos, E.S. (2007). On the extraction and antioxidant activity of phenolic compounds from winery wastes. Food Chemistry, 104(3), 1206-1214. https://doi.org/10.1016/ j.foodchem.2007.01.068 
Lipkovska, N.A., Barvinchenko, V.N. and Fedyanina, T.V. (2014). Dependence of the solubility of natural flavonoids in water on the concentration of miramistin, polyvinylpyrrolidone, and human serum albumin. Russian Journal of Physical Chemistry A, 88(5), $\quad$ 881-885. https://doi.org/10.1134/ S0036024414050161

Madruga, M.S., de Albuquerque, F.S.M., Silva, I.R.A., do Amaral, D.S., Magnani, M. and Queiroga Neto, V. (2014). Chemical, morphological and functional properties of Brazilian jackfruit (Artocarpus heterophyllus L.) seeds starch. Food Chemistry, 143, 440-445. https://doi.org/10.1016/ j.foodchem.2013.08.003

Mena, P., Calani, L., Bruni, R. and Del Rio, D. (2015). Bioactivation of high-molecular-weight polyphenols by the gut microbiome. In Tuohy, K. and Rio, D.D. (Eds.) Diet-Microbe Interactions in the Gut. Effects on Human Health and Disease., p. 73-101. USA: Academic Press. https://doi.org/10.1016/B978-0-12407825-3.00006-X

Ojwang, A.R., Muge, E.K., Mbatia, B., Mwanza, B., Lee, J.W. and Ogoyi, D.O. (2017). Comparative analysis of phytochemical composition and antioxidant Activities of methanolic extracts of leaves, roots and bark of Jackfruit (Artocapus heterophyllus) from selected regions in Kenya and Uganda. Journal of Advances in Biology and Biotechnology, 16(1), 1-13. https://doi.org/10.9734/ JABB/2017/37355

Osarumwense, P.O., Okunrobo, L.O., Uwumarongieilori, E. and Lucky, O.O. (2013). Phytochemical screening, proximate and elemental analysis of Citrus sinensis peels (1.). Journal of Applied Science and Environmental Management, 17(1), 47-50.

Perez, V. and Chang, E.T. (2014). Sodium-to-Potassium Ratio and Blood Pressure, Hypertension, and Related Factors. Advances in Nutrition, 5(6), 712-741. https://doi.org/10.3945/an.114.006783

Prakash, O., Kumar, R., Mishra, A. and Gupta, R. (2009). Artocarpus heterophylus (Jackfruit): An Overview. Pharmacognosy Reviews, 3(6), 353-358.

Rohman, A., Riyanto, S., Yuniarti, S., Utami W.R. and Mulatsih, W. (2010). Antioxidant activity, total phenolic and total flavonoids of extracts and fraction of red fruit. International Food Research Journal, 17, 97-106.

Romelle, F.D., Ashwini, R.P. and Manohar, R.S. (2016) Chemical composition of some selected fruit peels. European Journal of Food Science and Technology, 4(4), 12-21.

Shanmugapriya, K., Saravana, P.S., Payal, H., Mohammed, S.P. and Binnie, W. (2011). Activity, total phenolic and flavonoid contents of Artocarpus heterophyllus and Manilkara zapota seeds and its reduction potential. International Journal of Pharmacy and Pharmaceutical Sciences, 3(Suppl. 5), 256-260.

Shitan, N. (2016). Secondary metabolites in plants: transport and self-tolerance mechanisms. Bioscience, Biotechnology, and Biochemistry, 80(7), 1283-1293. https://doi.org/10.1080/09168451.2016.1151344

Sreeletha, A.S., Lini, J.J., Dhanyalekshmi, C.S., Sabu, K.R. and Pratap, C.R. (2017). Phytochemical, Proximate, Antimicrobial, Antioxidant and FTIR Analyses of Seeds of Artocarpus heterophyllus Lam. Advances in Biotechnology and Microbiology, 5(1), 555653.

https://doi.org/10.19080/

AIBM.2017.05.555653

Swami, S.B., Thakor, N.J., Haldankar, P.M. and Kalse, S.B. (2012). Jackfruit and Its many functional components as related to human health: A Review. Comprehensive Reviews in Food Science and Food Safety, 11(6), 565-576. https://doi.org/10.1111/ j.1541-4337.2012.00210.x

Sylvie, D.D., Anatole, P.C., Cabral, B.P. and Veronique, P.B. (2014). Comparison of in vitro antioxidant properties of extracts from three plants used for medical purpose in Cameroon: Acalypha racemosa, Garcinia lucida and Hymenocardia lyrata. Asian Pacific Journal of Tropical Biomedicine, 4(Suppl. 2), S625-S632. https://doi.org/10.12980/ APJTB.4.201414B168

Tambe, V.D. and Bhambar, R.S. (2014). Estimation of total phenol, tannin, alkaloid and flavonoid in Hibiscus tiliaceus Linn. wood extracts. Research and Reviews: Journal of Pharmacognosy and Phytochemistry, 2(4), 41-45.

Teixeira, T.S., Cássia do Vale, R., Almeida, R.R., Ferreira, T.P. and Gustavo Guimarães, L.L. (2017). Antioxidant potential and its correlation with the contents of phenolic compounds and flavonoids of methanolic extracts from different medicinal plants potential. Revista Virtual de Química, 9(4), 15461559. https://doi.org/10.21577/1984-6835.20170090

Toh, P.Y., Leong, F.S., Chang, S.K., Khoo, H.E. and Yim, H.S. (2016). Optimization of extraction parameters on the antioxidant properties of banana waste. Acta Scientarum Polonorum Technologia Alimentaia, 15(1), 65 - 78. https://doi.org/10.17306/ J.AFS.2016.1.7

Torti, S., Dearing, D. and Kursar, T. (1995). Extraction of Phenolic Compounds from fresh leaves: A comparison of Methods. Journal of Chemical Ecology, 21, 117-125. https://doi.org/10.1007/ BF02036646 